\title{
Ensaio Pictórico - Papel do Meio de Contraste lodado na Tomografia Computadorizada da Face
}

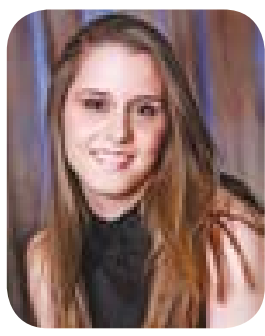

\author{
Marianna Machado Oliveira' ${ }^{1}$, Cristiane Abbehusen ${ }^{1}$
}

\section{RESUMO}

A Tomografia Computadorizada (TC) sem contraste venoso é o método de escolha para o estudo dos seios da face, pois as patologias inflamatório-infecciosas são as mais comuns e o estudo por imagem é solicitado para avaliar a extensão da doença, detectar variações anatômicas e auxiliar no planejamento do tratamento cirúrgico-endoscópico. A injeção do contraste venoso é reservada para a suspeita clínica de complicações orbitárias e intracranianas. Neste estudo, são demonstrados alguns sinais tomográficos que sugerem a presença de uma neoplasia em permeio ao processo inflamatório e, consequentemente, também indicam o uso do contraste venoso, representados por áreas com densidade tomográfica diferente no seu interior e por alterações ósseas subjacentes.

DESCRITORES: tomografia computadorizada da face, contraste iodado, tumores nasossinusais, complicações de rinossinusites.

\section{INTRODUÇÃO}

As patologias da cavidade nasal e dos seios da face, sejam inflamatório-infecciosas, sejam tumorais, são de grande importância clínica, tanto pela elevada frequência e impacto econômico das primeiras quanto pela morbidade e mortalidade, relacionadas sobretudo às neoplasias malignas. ${ }^{1,2}$

A TC é o principal método de imagem para o estudo das patologias das cavidades nasais e dos seios paranasais. ${ }^{1}$ Nas doenças inflamatório-infecciosas, o papel da TC é confirmar o diagnóstico quando os sintomas são atípicos, demonstrar a extensão da doença, avaliar a perviedade das vias de drenagem dos seios paranasais e descrever as variantes anatômicas, particularmente naqueles pacientes candidatos ao tratamento cirúrgico-endoscópico nasal. Para estes propósitos, o uso do contraste endovenoso geralmente é dispensado, ficando reservado para a suspeita clínica de complicações intraorbitárias e intracranianas das rinossinusites. ${ }^{1,3,4}$

As neoplasias nasossinusais primárias são menos frequentes e nos estágios iniciais produzem pouco ou nenhum sintoma, podendo ser confundidas com patologias inflamatórias e ter seu diagnóstico tardio. ${ }^{2} \mathrm{O}$ radiologista deve estar atento, na avaliação tomográfica de rotina da face sem contraste venoso, para perceber sinais tomográficos que sugiram a presença de um tumor focal, obstruindo as vias de drenagem dos seios, como a causa do processo inflamatório, e indicar a administração do meio de contraste iodado.

O objetivo deste trabalho é descrever e ilustrar as principais indicações e a importância do uso do meio de contraste endovenoso nos exames de Tomografia Computadorizada da Face.

\section{INDICAÇÕES DO CONTRASTE VENOSO}

Os tumores epiteliais são os mais comuns da cavidade nasal, destacando-se os papilomas, dentre os benignos, e os carcinomas de células escamosas, adenocarcinomas, carcinomas de células salivares e tumores neuroendócrinos, dentre os malignos. Outros tumores benignos e malignos ainda mais raros são o nasoangiofibroma e o linfoma e o estesioneuroblastoma, respectivamente. ${ }^{5} \mathrm{O}$ seio maxilar é o principal sítio das neoplasias malignas, correspondendo a $60-70 \%$ dos casos, seguido da cavidade nasal, representando $20-30 \%$, e do labirinto etmoidal, $10-15 \%$. Raramente são encontrados nos seios frontal e esfenoidal. ${ }^{5}$

Alguns dados da história clínica fornecida podem alertar para a possibilidade de lesão neoplásica sinonasal e corroborar para a indicação do contraste venoso, dentre eles: sexo masculino, idade superior a 50 anos, presença de epistaxe e sintomas extranasais, como dor facial e sintomas dentários e orbitários. ${ }^{6}$

Os principais achados tomográficos que podem indicar a presença de uma neoplasia subjacente são: 1) obstrução unilateral e assimétrica de uma das fossas 
nasais, pois os tumores, ao contrário da polipose nasal, são mais frequentemente unilaterais ${ }^{6}$; 2) presença de uma área com densidade tomográfica diferente, geralmente aumentada, em permeio às secreções nasossinusais, sendo importante a avaliação das imagens com janela de partes moles; 3) destruição óssea regional; 4) reação óssea espiculada na parede do seio ou da cavidade nasal acometida ${ }^{5,6}$; e 5) envolvimento de partes moles extrassinusais ${ }^{6}$. A reação óssea espiculada descrita é considerada como um achado de imagem sugestivo do diagnóstico de papiloma e indicativo do local de origem do tumor, bem como a região mais provável de ocorrência de recidiva tumoral pós-tratamento, devendo ser cuidadosamente ressecada durante a cirurgia. ${ }^{5,6}$

A administração do meio de contraste endovenoso na TC, nestes casos, possibilitará o diagnóstico de uma lesão tumoral em permeio às secreções mucosas que não se realçam pelo contraste, assim como poderá melhor avaliar a invasão de estruturas adjacentes e realizar o estadiamento locorregional de tumores malignos. ${ }^{7,8}$

O padrão de realce pelo contraste auxilia também na caracterização de tumores, como nas neoplasias hipervasculares, a exemplo do nasoangiofibroma e hemangiopericitoma, que se realçam intensamente pelo contraste, semelhante às estruturas vasculares. Por sua vez, uma impregnação com aspecto "ceribriforme" pelo contraste venoso é muito característica dos papilomas invertidos, devido ao crescimento endofílico do epitélio superficial para o interior do estroma adjacente, diferentemente dos pólipos inflamatórios antrocoanais, os quais apresentam um realce discreto e homogêneo. Essas lesões apresentam achados de imagem superponíveis no estudo sem contraste venoso.

\section{SÉRIE DE CASOS}

As imagens apresentadas foram selecionadas retrospectivamente dentre exames de TC da face de pacientes encaminhados para investigação diagnóstica de rinossinusites inflamatórias nas cavidades nasais e seios da face, obtidas do arquivo do Serviço de Imagem do Hospital Santa Izabel da Santa Casa da Bahia, nos quais o contraste venoso foi indicado pela suspeita de uma neoplasia concomitantemente, devido à presença de um ou mais dos sinais tomográficos acima relatados.

\section{CASO 1}

Paciente do sexo masculino, 63 anos, com queixa de obstrução nasal e coriza, apresentando apenas cornetos nasais hipertróficos ao exame físico.

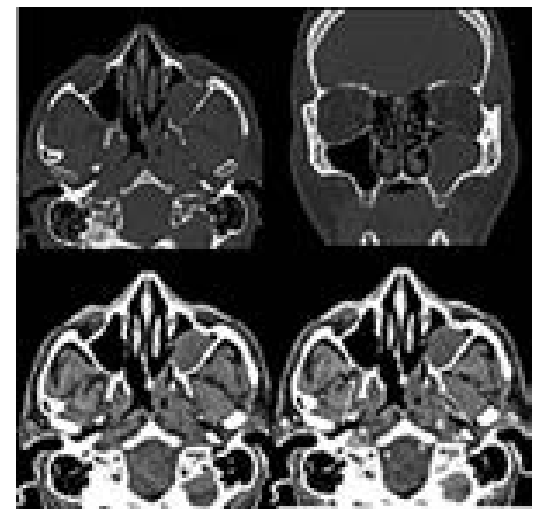

Figura 1 - Pólipo antrocoanal

As imagens multiplanares de TC da face sem contraste com janela óssea demonstraram o preenchimento parcial do antro maxilar esquerdo por uma formação polipoide com extensão para a fossa nasal e rinofaringe deste lado, através do óstio acessório do seio maxilar. O realce discreto e homogêneo, assim como a ausência de alterações ósseas em associação, sugeriu a possibilidade de pólipo inflamatório antrocoanal, confirmada histologicamente.

\section{CASO 2}

Paciente do sexo masculino, 55 anos, com obstrução nasal crônica à esquerda há 9 anos, associada à rinorreia intermitente de odor fétido neste lado e à episódios de epistaxe. Na rinoscopia, foi identificada uma lesão polipoide no meato médio, obliterando grande parte da fossa nasal esquerda.

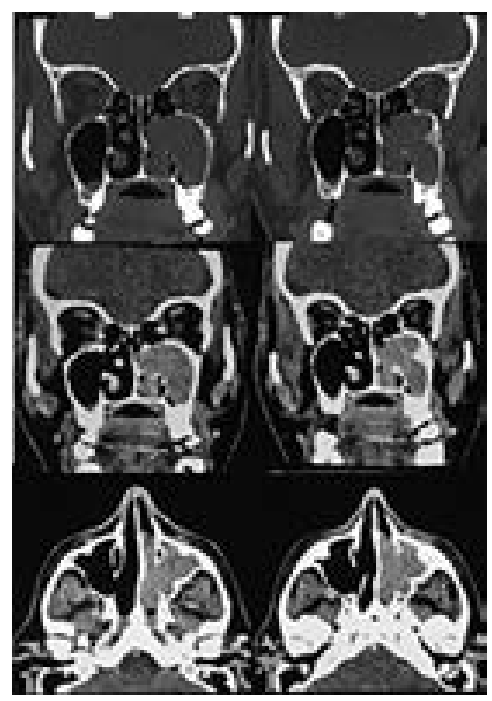

Figura 2 - Papiloma oncocítico 
A TC demonstrou uma formação expansiva, preenchendo o seio maxilar esquerdo e se estendendo para a fossa nasal ipsilateral, através do infundíbulo etmoidal alargado. A obliteração unilateral da fossa nasal indicou o uso do contraste venoso. O realce bastante heterogêneo da formação foi sugestivo de uma lesão neoplásica. Outro achado tomográfico indicativo de neoplasia foi a reação óssea espiculada na parede lateral do seio maxilar acometido. O estudo anatomopatológico diagnosticou papiloma oncocítico.

\section{CASO 3}

Paciente do sexo feminino, 52 anos, com queixa de rinorreia, obstrução nasal e epistaxe à esquerda. $\mathrm{Na}$ rinoscopia, foi observada hipertrofia da concha nasal inferior direita e secreção amarelo-esverdeada na fossa nasal esquerda.

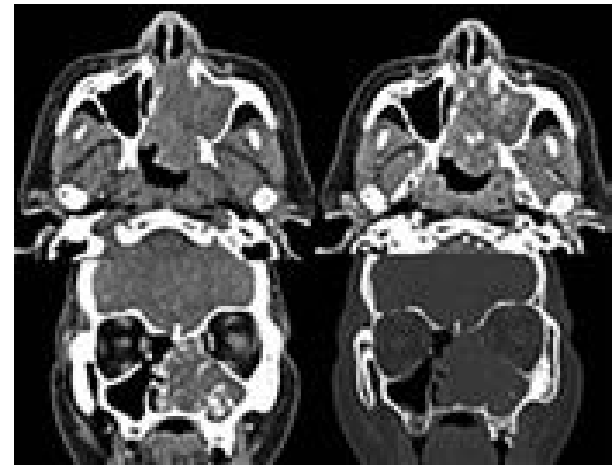

Figura 3 - Papiloma invertido

Neste caso, dois sinais tomográficos indicaram o uso do meio de contraste. Primeiro, a presença de uma volumosa formação expansiva preenchendo completamente a fossa nasal e o seio maxilar à esquerda. E segundo, a extensa destruição óssea do labirinto etmoidal, da parede medial do seio maxilar e dos cornetos médio e inferior homolaterais. As imagens com contraste venoso demonstraram um realce heterogêneo e intenso da lesão, num padrão "cerebriforme", indicando uma neoplasia, possivelmente papiloma invertido. $O$ estudo anatomopatológico confirmou este diagnóstico.

\section{CASO 4}

Paciente do sexo feminino, de 70 anos, com história de epistaxes recorrentes pela fossa nasal direita há dois anos.

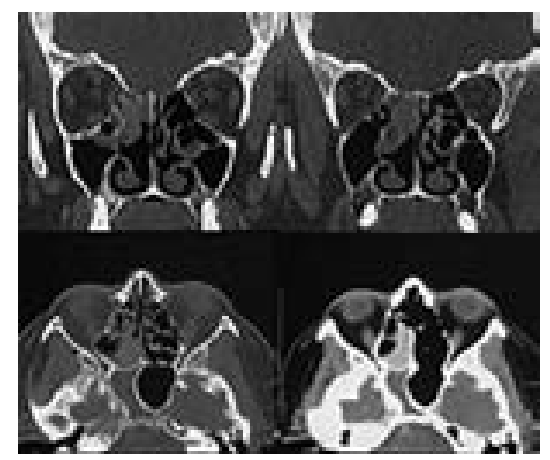

Figura 4 - Hemangiopericitoma sinonasal

As imagens de TC de face sem contraste demonstraram um material preenchendo os meatos nasais médio e superior direitos, células etmoidais e o seio esfenoidal deste lado. A presença de uma área focal com densidade diferente em permeio, localizada no meato superior, bem como a destruição óssea do corneto nasal médio, indicaram o contraste venoso, particularmente quando se trata de paciente idoso com história de epistaxe recorrente. A fase contrastada do exame evidenciou nitidamente uma lesão tumoral sólida com realce intenso e homogêneo, diferentemente da secreção líquida acumulada no seio esfenoidal. $O$ diagnóstico histológico foi hemangiopericitoma.

\section{CASO 5}

Paciente do sexo masculino, 13 anos, com obstrução nasal e epistaxe à direita há 6 meses, sem progressão do aparelho de endoscopia nasal neste lado.

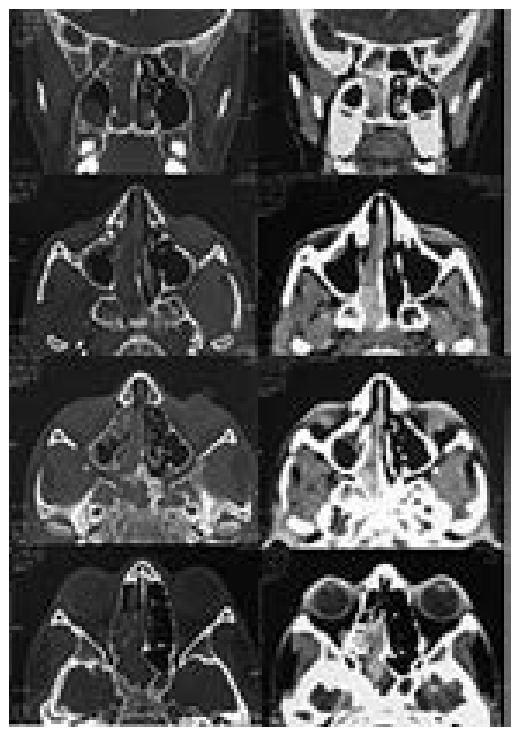

Figura 5 - Nasoangiofibroma 
Neste paciente, a TC sem contraste demonstrou obliteração unilateral da fossa nasal direita, indicando o uso do contraste, corroborado pela história clínica. Era também observada destruição óssea do plano esfenoidal. Após a administração do contraste venoso, notou-se uma lesão expansiva sólida intranasal direita, junto ao forame esfenopalatino, com intensa impregnação pelo contraste. Os dados clínicos e estes achados de imagem foram indicativos de nasoangiofibroma, confirmado pela histologia.

\section{CONSIDERAÇÕES FINAIS}

A Tomografia Computadorizada sem contraste é o método de escolha para o estudo da face. As patologias inflamatório-infecciosas são as mais comuns, geralmente bilaterais, e prescidem do estudo com contraste venoso.

O médico radiologista, entretanto, deve estar atento aos sinais tomográficos de uma neoplasia subjacente: 1) obstrução unilateral de uma das fossas nasais; 2) área com densidade tomográfica diferente em permeio às secreções nasossinusais; 3) destruição óssea regional; 4) reação óssea espiculada na parede do seio ou cavidade nasal acometido; e 5) envolvimento de partes moles extrassinusais.

Apesar da Ressonância Magnética (RM) poder ser solitada como complementação diagnóstica, a TC com contraste venoso pode fornecer os dados necessários para o diagnóstico e o planejamento terapêutico das neoplasias nasossinusais. Como a TC é um método de imagem mais amplamente difundido e de custo econômico inferior, a RM ficaria reservada para a avaliação de invasão da base do crânio e de disseminação perineural, situações em que este método apresenta uma maior capacidade diagnóstica. $^{7}$

Portanto, o contraste endovenoso iodado tem indicações precisas na TC e o médico radiologista precisa estar atento a estes sinais tomográficos.

\section{REFERÊNCIAS}

1. Cornelius RS, Martin J, Wippold FJ, et al. ACR Appropriateness Criteria Sinonasal Disease. J Am Coll Radiol 2013; 10:241-246.

2. Eggesbo HB. Imaging of sinonasal tumours. Cancer Imaging 2012; 12: 136-152.

3. Mafee MF, Tran BH, Chapa, AR. Imaging of Rhinosinusitis and Its Complications. Clinical Reviews in Allergy \& Immunology 2006; 30:165-185.

4. Eggesbo HB. Radiological imaging of inflammatory lesions in the nasal cavity and paranasal sinuses. Eur Radiol 2006; 16: 872-888.
5. Tumours of the Nasal Cavity and Paranasal Sinuses. WHO.

6. Nair S, James E, Awasthi S, et al. A Review of the Clinicopathological and Radiological Features of Unilateral Nasal Mass. Indian J Otolaryngol Head Neck Surg 2013, 65(Suppl 2):S199-S204.

7. Gomaa MA, Hammad MS, Abdelmoghny A, et al. Magnetic Resonance Imaging Versus Computed Tomography and Different Imaging Modalities in Evaluation of Sinonasal Neoplasms Diagnosed by Histopathology. Clinical Medicine Insights: Ear, Nose and Throat 2013; 6: 9-15.

8. Sivalingam J, Sarawagi R, Raghuwanshi S, et al. Sinonasal Neoplasia - Clinicopathological Profile And Importance of Computed Tomography. Journal of Clinical and Diagnostic Research 2015, 9(6): TC01-TC04.

1- Serviço de Imagem do HSI Endereço para correspondência: mariana_mmo@hotmail.com 